\title{
HORROR E HUMOR NO CANTO IX DA ODISSEIA: UMA LEITURA DO EPISÓDIO DO CICLOPE PROPOSTA POR DEMÉTRIO NO TRATADO SOBRE O ESTILO*
}

\author{
Gustavo Araújo de Freitas $\star \star$ \\ Universidade Federal de Minas Gerais
}

\begin{abstract}
A brief analysis of the entries made by Demetrius in the treatise On Style, in the Cyclop episode, in the book IX of the Odyssey reveals, beyond a remarkable interest in the passage of the work of Homer, peculiar features of an accurate literary criticism. In this criticism, as it should be, we emphasize the horror of Polyphemus character, his monstrous appearance and actions. However, references to the famous speech of the Cyclops, in verses 369 and 370, reveal more than that: they emphasize the comical nature of the passage. Going forward, this character is not only examined from a perspective of horror but also presented as an element that intensifies it, within an approach that has no parallel in any other treatise of Antiquity.

KEYWORDS: Odyssey; Cyclops; Homer; Demetrius; On style.
\end{abstract}

exemplo de grande parte dos tratados de retórica da Antiguidade, nos quais o prestígio de Homero é assaz reconhecido, Sobre o estilo de Demétrio demonstra um interesse patente pelo poeta, o que pode ser

\footnotetext{
* Este artigo foi concebido a partir da dissertação de mestrado defendida pelo autor no $1^{\circ}$ semestre de 2011, dentro do Programa de Pós-Graduação em Estudos Literários, na área de concentração de Estudos Clássicos, da Faculdade de Letras da UFMG, intitulada "Sobre o estilo" de Demétrio: um olhar crítico sobre a literatura grega (tradução e estudo introdutório do tratado), sob a orientação do Prof. Dr. Jacyntho José Lins Brandão.


Literários da Faculdade de Letras da UFMG, bolsista CAPES/ REUNI.
} 
comprovado pelo próprio número de citações tomadas tanto da Ilíada quanto da Odisseia e que fazem de seu autor, dentre todos os reportados


Ao certo, também os comentadores modernos não o deixaram de notar, bem como não lhes passou desapercebido o fato de que os trechos selecionados por Demétrio - e não apenas de Homero, como também dos demais autores -, uma vez submetidos à sua avaliação, apontam não apenas para um fim prático, mas também para um julgamento, ${ }^{2}$ ou, dito de outra forma, para uma crítica literária. ${ }^{3}$

\footnotetext{
${ }^{1}$ Para um panorama acerca do número de menções a esses autores e citações, cf. Chiron, P. Un rhéteur méconnu: Démétrios (Ps.- Démétrios de Phalère). Essai sur les mutations de la théorie du style à l'époque hellénistique. Paris: Librairie Philosophique J. Vrin, 2001, p. 383-389.
}

${ }^{2}$ Oportunamente, lanço mão dos mesmos termos utilizados por Schenkeveld (Studies in Demetrius “On style”. Amsterdam: A. Hakkert, 1964, p. 51-52).

${ }^{3}$ Lembremos que a relevância da crítica literária contida no tratado-e que se demonstra na presença de um grande número de reflexões sobre as mais diversas passagens da literatura grega - é tal que suscitou o fecundo debate entre os comentadores se, de fato, estaríamos diante de um manual de retórica ou de uma obra de crítica literária. Innes chega a afirmar que, à diferença de muitas outras fontes, particularmente em latim, não haveria nele uma propensão para a oratória [Demetrius. "On style" (in Aristotle, v. XXIII). London: Harvard University Press, 2005, p. 312]. Grube, sem que, ao certo, desconsidere a vinculação do tratado à retórica, em dado momento, comenta que o interesse de Demétrio seria pela literatura, mais do que pelos processos, casos ou argumentos ligados aos tribunais (The Greek and Roman critics. Indianapolis: Hackett Publishing Company, Inc., 1995, p. 119). Em outra ocasião, o mesmo autor volta a salientar que os interesses de Demétrio são obviamente literários, mais do que retóricos no sentido estrito, e lembra que os oradores são frequentemente mencionados, mas apenas como um tipo de literatura entre vários. Estaríamos, assim, diante de um exemplo de crítica literária, da parte de um homem treinado em retórica, mas não um mero retórico (A Greek critic: Demetrius "On style”. Toronto: University of Toronto Press: 1961, p. 22). Em consonância, Kennedy comenta que, além de conter as lições de como se escrever bem, o PH é também uma sensível peça de crítica literária (Classical rhetoric E its christian E secular tradition from ancient to modern times. 2nd ed., rev. and enl. Chapel Hill: University of North Carolina Press, 1999, p. 131). Schenkeveld defende, no entanto, a ideia de que o tratado de Demétrio tenha, de fato, sido um manual de retórica (op. cit., 1964, p. 51-52), e, ao certo, é também dele a melhor resposta para a questão, embora não tanto em seu trabalho citado acima, mas em seu artigo intitulado "The intended public of Demetrius's 'On style': the place of the treatise in the Hellenistic educational system" (Rhetorica. Berkeley, vol. XVIII, n. 1, p. 29-48, 2000). Nesse último, o autor situa a obra no contexto educacional do 
Contudo, apesar da inconteste presença dessa crítica, grande parte das reflexões de Demétrio sobre os autores que menciona - e, logo, também sobre o poeta - resta ainda pouco explorada pelos estudiosos. Do mesmo modo que permanece ainda na sombra um dos pontos de vista mais peculiares - e não só entre os críticos antigos como também entre os modernos - sobre uma das passagens mais famosas de Homero, a do episódio do Ciclope no canto IX da Odisseia.

Em considerações a versos que compõem a cena, Demétrio enfatiza, pois, o horror da personagem Polifemo, figura monstruosa e de ações selvagens já bem conhecidas, mas que, em dado momento, revelaria inesperadamente o seu lado cômico. E, mais do que isso, essa surpreendente faceta não apenas se manifestaria em dada ocasião, como também faria dele uma personagem ainda mais assustadora, dentro de uma perspectiva sem paralelo no contexto da crítica literária da Antiguidade. ${ }^{4}$

período helenístico, em uma fase do aprendizado em que a crítica literária não apenas se faz presente como se coloca a serviço da própria retórica (cf. infra). Nesse ponto, concordamos também com o autor no que concerne à opinião de Classen; de fato, as muitas críticas proferidas por Demétrio são quase sempre subservientes às lições que ele escolhe para ensinar. A esse respeito, Sobre o estilo é, assim como O tratado do sublime de Longino e Sobre o arranjo das palavras de Dionísio de Halicarnasso, uma feliz instância do ensino retórico. Ao certo, sem que desconsideremos a relevância do trabalho de Classen, tanto na problematização dos limites da retórica e da crítica literária, quanto no valioso tratamento acerca dos críticos da Antiguidade, pensamos, a exemplo de Schenkeveld, que, no que concerne ao tratado de Demétrio, assim como também aos de Dionísio de Halicarnasso e Longino, as informações daquele autor mostram-se antes imprecisas (Schenkeveld, op. cit., 2000, p. 47-48/ Classen, C. J. Rhetoric and literary criticism. Their nature and their functions in Antiquity. Mnemosyne. Leiden, vol. XLVIII, p. 513-535, 1995, p. 525-528).

${ }^{4}$ Há, ao certo, também comentadores modernos que apontam aspectos cômicos na passagem. Reece, por exemplo, considera a cena uma "paródia do tema da hospitalidade", e, ao longo de seu capítulo sobre Polifemo [Polyphemus ("Od". 9. 105-564). In: (org.). The stranger's welcome. Oral theory and the aesthetics of the homeric hospitality scene. Ann Arbor: The Michigan University Press, 1993, p. 127], lembra alguns momentos cômicos do episódio. Salienta o autor: It has been generally noted that Homer has characterized his hero as exceptionally resourceful (...) and that he has characterized his ogre as exceptionally contemptuous of the gods - thus placing the opposition of Polyphemus and Odysseus into a theological context - but at the same time as somewhat pathetic (Polyphemus' conversation with hisfavorite ram)./ Acerca de aspectos cômicos no episódio, cf. ainda P. Pucci, "The I and the other in Odysseus's story of the Cyclopes" [in: (org.). The song of the sirens. Essays on Homer. Lanham: Rowman \& Littlefield Publishers, 1998, p. 113-130]. Porém, é digno de nota o fato de que a abordagem de 
Mas para que, de fato, possamos melhor apreender os múltiplos aspectos dessa vária crítica de Demétrio ao episódio, parece oportuno, antes de nos determos mais precisamente nas menções ao mesmo, procurar entender um pouco mais as bases em que tal crítica se constrói, ou, melhor dizendo, como afinal ela se define a partir da relação com o contexto e o plano do desenvolvimento teórico do autor.

\section{A crítica ao episódio no contexto da obra}

Antes de mais nada, deve-se atentar para o fato de que, a despeito das inúmeras dúvidas que rondam o referido texto no que diz respeito à questão envolvendo sua data e autoria, ${ }^{5}$ é razoável que o consideremos, por características presentes nele próprio, um manual de retórica, e,

Demétrio apresenta uma sutil diferença na associação direta do elemento do horror ao do cômico (cf. infra). Mesmo Reece, ao indicar a passagem de Demétrio, não adentra essa discussão (op. cit., p. 139).

${ }^{5}$ De fato, durante anos, essa questão tem sido alvo de incontáveis controvérsias, que ainda hoje não estão de todo resolvidas. Ao longo do tempo, os estudiosos propuseram datas que vão desde o séc. III a.C. ao séc. II d.C. (para uma melhor apreciação acerca dessa questão cf. Chiron, op. cit., 2001, p. 311-370/ Chiron, P. Démétrios. "Du style". Paris: Les Belles Lettres, 1993, XIII-XL/Innes, op. cit., 2005, p. 312-321). Se tomarmos, no entanto, os estudos mais recentes, constataremos que há uma tendência a aproximar o tratado do contexto do período helenístico; portanto, em uma datação anterior ao séc. I d.C., como sugerida por Roberts, embora, de fato, ele não tenha desconsiderado a possibilidade do séc. I a.C. (cf. Roberts, W. R. Demetrius "On style", the Greek text of Demetrius "De elocutione". Edited after the Paris manuscript, with introduction, translation, facsimiles, etc. Cambridge: Cambridge University Press, 1902, p. 64). Entre os estudos, destacam-se: o de Grube, que sugere uma datação em 270 a.C. (op. cit., 1961, p. 56), mas que, por sua vez, é questionada pelo de Schenkeveld, que situa o tratado no século I d.C., mas refletindo o segundo ou o primeiro século a.C. (op. cit., 1964, p. 147); temos ainda o de MorpurgoTagliabue, que propõe que Demétrio se encontre em fins do período alexandrino, entre o aristotelismo estoicizante e a cultura greco-romana (Demetrio: dello stile. Roma: Edizioni dell'Ateneo, 1980, p. 141); além do importante estudo de Chiron, supracitado, que situa a obra em fins do segundo século ou, de modo mais verossímil, em meados do século primeiro a.C. (op. cit., 2001, p. 370); temos também o estudo de Innes, que propõe o tratado no séc. I a.C. mas considerando que, ao certo, reflete concepções do séc. II a.C. (op. cit., 2005, p. 312-321). Ainda quanto à autoria dada por indicações presentes em manuscritos, cf. Chiron, op. cit., 1993, p. XV-XVIII/Innes, op.cit., 2005, p. 312. 
assim, que o insiramos no contexto da educação vigente no período helenístico, situando-o por volta do séc. I a.C. ${ }^{6}$

Quanto a isso, faz-se oportuna a discussão proposta por Schenkeveld acerca do público do $\mathrm{PH}^{7}$ a qual se pauta justamente na relação professor-aluno como base da composição da obra. ${ }^{8}$ Segundo o comentador, Demétrio estaria escrevendo seu livro para leitores que já teriam completado cursos de gramática - e, por essa razão, ele poderia citar Homero em uma versão reduzida, referir-se ao hexâmetro e a outros metros, bem como às figuras de estilo, sem se aprofundar - e que também já teriam passado pelos cursos iniciais de retórica, onde teriam estudado e praticado os progymnásmata e lido e decorado várias passagens famosas de autores de prosa. ${ }^{9}$ Nessa nova fase do aprendizado,

${ }^{6}$ Chiron oportunamente lembra que esse seria uma das únicas fontes de informação sobre a estilística pós-aristotélica anterior a outras obras mais conhecidas, como a "Retórica a Herênio", aquelas de Cícero e as de Dionísio de Halicarnasso (op. cit., 1993, p. XII). Acerca de sua inserção no período helenístico, cf. ainda Pernot, L. La Rhétorique dans l'Antiquité. Paris: Librairie Génerale Française, 2000, p. 86/ Kennedy, G. A. A new history of classical rhetoric. Princeton, New Jersey: Princeton University Press, 1994, p. 89. Quanto ao sistema educacional, lembra oportunamente Bompaire que ele teve pouca variação desde a época de Alexandre e também sem diferenças significativas entre Grécia e Roma (cf. Bompaire, J. Lucien écrivan. Imitation et création. Paris: Les Belles Lettres, 2000, p. 35).

${ }^{7}$ Cf. Schenkeveld, op. cit., 2000, p. 29-31. Conforme salienta o autor, parece lógico que, de algum modo, o público determine o conteúdo da obra, bem como o nível de compreensão por ela admitido. A esse respeito, o comentador também ressalta que, embora de diversos tratados da Antiguidade possamos ter algum conhecimento quanto ao leitor ou ao público a quem se dirigem - ou porque o autor os identifica, ou através de indicações no texto-, em relação a muitos outros estamos na completa escuridão, tendo, assim, que descobrir por meio de inferências, e esse último é o caso do de Demétrio.

${ }^{8}$ Cf. Schenkeveld, op. cit., 2000, p. 35-38: o caráter didático sendo, pois, facilmente reconhecido na presença dos imperativos e formas verbais similares./ Cf. ainda Schenkeveld, op. cit., 1964, p. 51.

${ }^{9}$ Cf. Schenkeveld, op. cit., 2000, p. 40. Nesse ponto, parece oportuno lembrar o debate levantado por Innes, que contesta o autor (Schenkeveld, op. cit., 1964, p. 80) por ter afirmado que Demétrio teria sido um escritor de um manual de estilística para futuros oradores (orators-to-be). A autora tê-lo-ia questionado, então, porque haveria matérias não propriamente de oratória (non-oratorical) no caso do estilo grandioso, como as batalhas navais (\$75), e tão poucos exemplos da oratória no $P H$ [Innes, D. C. Reviewed work(s): studies in Demetrius 'On style' by Dirk Marie 
então, esses alunos partiriam para lições mais difíceis, comumente chamadas de declamationes. ${ }^{10}$

Em suma, estaríamos diante de um manual do orador em uma fase mais avançada do aprendizado, em que, conforme enfatizou Schenkeveld, a crítica literária não apenas se faz presente, como se torna um importante instrumento a serviço da retórica, ${ }^{11}$ sendo, pois, consolidada no procedimento de seleção dos melhores exemplos a serem avaliados positiva ou, por vezes, negativamente, sob a ótica da abordagem conveniente dos assuntos por eles apresentados. Além disso, seu público explicaria ainda, de modo um tanto satisfatório, o destaque conferido à poesia e, sobretudo, a Homero: ${ }^{12}$ de um lado, a importância da crítica literária, e, de outro, o fato de os pontos levantados já terem sido

Schenkeveld. The classical review, new series. Cambridge, vol.XVI, n. 3, p. 315-317, dec. de 1966, p. 316]. O autor se defende, contudo, dizendo que, na ocasião de seu livro supracitado, de fato não esclarecera quem seriam esses 'futuros oradores', o que, pelo que diz em seu artigo, não só se torna mais nítido, como também justifica a consequente presença de assuntos não propriamente ligados à oratória.

${ }^{10}$ Conforme complementa o autor, teríamos de supor que, no período helenístico do terceiro/ segundo século, as declamationes não se restringiriam à prática forense $\mathrm{e}$ deliberativa, mas também ao discurso epidítico (cf. Schenkeveld, op. cit., 2000, p. 47). É também oportuno lembrar que embora o autor houvesse sugerido em Studies in Demetrius 'On style' uma datação para o tratado em I d.C. (cf. supra nota 5), em seu artigo ele assume a mesma posição de Innes, considerando aquele como tendo sido composto no primeiro século a.C., mas ainda com a condição de que o conteúdo da obra em muitos aspectos reflita concepções do segundo século a.C. ou de antes disso (op. cit., 2000, p. 35). Para uma percepção mais ampla acerca do ensino literário e a questão da mimese cf. Bompaire, op. cit., p. 33-97.

${ }^{11}$ Cf. Schenkeveld, op. cit., 2000, p. 47. Nesse ponto, concordamos com a posição do autor com relação àquela de Classen (cf. supra nota 5).

${ }^{12}$ De fato, Demétrio demonstra interesse também por outros poetas, tais como Safo ( $\$ 106$ ?, 127, 132, 140, 141,142?, 146, 148, 162, 166, 167; os pontos de interrogação marcam as passagens em que as citações são de atribuição discutida); Arquíloco (\5);


( $\$ 189)$; Teógnis $(\$ 85)$. Porém, de nenhum outro possuímos tanta informação quanto de Homero; o número de menções a ele sobrepuja, e muito, o dos demais, sendo lembrado em quarenta e duas ocasiões (acerca das citações extraídas da Ilíada, cf. $\$ 7,25,48,54,56,57,61,64,79,81,82,83,94,105,111,124,189,200,209,210,219$, 220, 255, 257; Odisseia, cf. \52, 57, 60, 72, 94, 107, 113, 129, 130, 133, 152, 164, 219, 262. Outras menções ao poeta: $₫ 5,12,36,150)$. Para um panorama acerca do número de menções a autores e citações, cf. ainda Chiron, op. cit., 2001, p. 383-389. 
pensados pelo gramático e de os exemplos já serem devidamente reconhecidos. ${ }^{13}$

E, afinal, se esse mesmo público poderia ser o motivo, como destacou Schenkeveld, do fato de não serem necessárias explicações detalhadas acerca de determinados assuntos, ${ }^{14}$ ele poderia justificar também, em grande medida, as eventuais lacunas nas reflexões críticas que acompanham várias das menções aos autores citados. E, nesse ponto, vale lembrar o que bem salientou Bompaire a propósito da educação no período: a iniciação à crítica ocorre na escola do gramático, ao menos



Assim, justifica-se também de modo bastante satisfatório a existência das lacunas nas reflexões de Demétrio acerca do episódio da Odisseia em questão, ${ }^{16}$ as quais, como se percebe, não podem ser vistas como meras faltas do autor, mas antes entendidas segundo as próprias condições admitidas pelo público a que seria destinada a obra, pelo menos a princípio. Logo, o intuito de buscar preencher, ainda que minimamente, essas lacunas legitima também a nossa tentativa de sistematizar essa crítica, partindo da relação de tais passagens com outras, também dispersas ao longo da obra, ou, mesmo, com as de outros tratados, dada a observância de diversos elementos comuns que as permeariam.

${ }^{13}$ Cf. Schenkeveld, op. cit., 2000, p. 44. Nesse sentido, é oportuno salientar que grande parte dos exemplos recolhidos dos poetas ilustra o emprego de recursos estilísticos que não se restringem à poesia, mas, ao invés disso, são também aplicáveis à prosa (à guisa de exemplo, cf. $\ 52,55,72,78-79,106-108$ ). Daí, o considerável número deles em um tratado cuja principal preocupação não é a princípio a poesia especificamente, mas o discurso de uma maneira geral. E ressalto a expressão "discurso de uma maneira geral", e não exatamente "prosa", porque, na maior parte do tempo, não se verifica uma preocupação maior em delimitar os dois referidos tipos de discurso, salvo em circunstâncias determinadas; ou seja, a distinção proposta nas linhas introdutórias e que será, de algum modo, mais presente na introdução do tratado, não é uma tônica na obra, além do que o próprio termo utilizado para referir-se à prosa, $\lambda$ óyos, ao longo do $P H$, não se aplica de forma estrita a ela, mas, ao contrário, algumas vezes é aplicado inclusive ao texto em verso. Acerca dessa terminologia, cf. Freitas, op. cit., p. 26-30.

${ }^{14}$ Os metros na poesia, por exemplo. Tampouco seria necessária uma definição sobre certos termos técnicos como as figuras (cf. supra). Ou, ainda, no que concerne às passagens extraídas dos autores clássicos, algumas teriam de ser citadas na íntegra, enquanto outras não teriam igual necessidade (cf. Schenkeveld, op. cit., 2000, p. 40).

${ }^{15}$ Cf. Bompaire, op. cit., p. 36.

${ }^{16}$ As quais se tornarão mais nítidas no prosseguimento de nossa análise. 
E, desse modo, teríamos, em linhas gerais, o contexto da obra e sua importância para se pensar a inserção da crítica ao episódio na mesma. $\mathrm{E}$, dito isso, então, o próximo passo é procurar entender como se dá essa inserção mais precisamente no plano do desenvolvimento teórico proposto pelo autor. E, antes de tudo, não poderíamos deixar de verificar o modo como as menções a Homero se distribuem ao longo do $P H,{ }^{17}$ pois se revela nisso também um traço essencial no contexto da crítica de Demétrio ao poeta, e que, por conseguinte, também se aplica ao episódio.

O que se constata, pois, é que embora o poeta seja, de fato, o autor com maior número de citações referentes ao estilo grandioso, seus versos são encontrados por todo o tratado: ora grandiosos, ora elegantes ou cômicos, por vezes simples, ou até mesmo veementes, eles são apresentados como componentes de uma obra rica e bemsucedida em virtude da grande quantidade de recursos estilísticos aplicados a uma quantidade igualmente expressiva de assuntos.

Com efeito, essa maneira de as menções a Homero e a sua obra estarem dispostas, ao longo da introdução e dos quatro capítulos, remete-nos, inevitavelmente, à "mescla de estilos", proposta nos parágrafos 36 e 37, onde se encontram considerações essenciais, ainda que gerais, a respeito da teoria dos quatro tipos elementares (oi $\alpha \dot{m} \lambda$ oî


riqueza estilística do poeta também se verifica nos versos referentes ao episódio do Ciclope; apresentados, pois, no decorrer dos quatro capítulos da obra, tais versos remetem-nos também a essa "mescla".

Ainda com relação a essa última, vale ressaltar que, por vezes, um exemplo serve a um tipo de estilo somente; nesse caso, tal "mescla" dar-se-ia pelos diferentes estilos empregados conforme a ocasião. No entanto, em outros momentos, o mesmo exemplo é utilizado como modelo para mais de um tipo de estilo, e essa observação, já antes feita por Schenkeveld, é oportuna, pois serve também à passagem que faz

\footnotetext{
${ }^{17}$ Para uma análise mais acurada acerca das menções aos poetas no decorrer da introdução e dos quatro capítulos, cf. Chiron, op. cit., 2001, p. 387-389.

${ }^{18}$ Vale lembrar que, na ocasião, após Demétrio discorrer acerca das respectivas denominações destes estilos, ele ressalta que os outros tipos seriam o resultado de uma mistura destes quatro, com exceção do grandioso e do simples, que nunca se misturariam, e como exemplo teríamos a prosa de Platão, Xenofonte, Heródoto, além, é claro, da poesia de Homero.
} 
menção aos versos 369 e 370 do canto IX da Odisseia. ${ }^{19}$ Tal como apresentada por Demétrio, a fala do Ciclope reproduz o horror, mas, ao mesmo tempo, possui certa comicidade, servindo como modelo

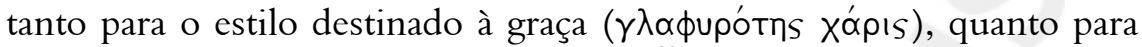



Dessa maneira, conclui-se que, num âmbito geral, as menções ao episódio apontam para uma "mescla de estilo" que se dá dos dois referidos modos: em linhas gerais, pelos tipos de estilo empregados em diferentes ocasiões, e, no caso particular da passagem supracitada, pelos tipos que se verificam no mesmo modelo. Lembremos, pois, que há seis passagens no $P H$ que discorrem acerca de versos que compõem o episódio no poema, sendo que três tratam de diferentes momentos - duas delas $(\$ 52,394)$ como modelo de elevação do estilo, e uma (\$219) exemplificando o bom emprego do estilo simples -, e as outras três ( $\$ 130,152$ e 262), que mencionam justamente a fala do Ciclope nos versos 369 e 370, enfatizando, como se disse, os traços estilísticos próprios do horror ao lado do cômico. ${ }^{21}$

Mas, sem dúvida, ainda que a "mescla de estilos" seja essencial para se pensar a crítica de Demétrio ao episódio, isso não significa, obviamente, que os comentários que envolvem cada menção ao mesmo se restrinjam a apontar a diversidade estilística do texto homérico. Pelo contrário, trata-se antes, conforme já mencionamos, de uma avaliação do modo de proceder do poeta da Odisseia, ou seja, do emprego conveniente dos recursos de estilo nas diferentes circunstâncias, o que implica uma observação dos elementos mais propriamente discursivos, ao lado, e de modo indissociável, do assunto tratado. E, desse modo, afinal, uma vez de posse das informações, descritas acima, do contexto da obra e de sua relação com a crítica ao episódio no tratado, o passo

\footnotetext{
${ }^{19}$ Cf. Schenkeveld, op. cit., 1964, p. 55: We may conclude therefore that to Demetrius mixture of styles means that even viewed from the same aspect, a passage may belong simultaneously to several types of style./ Cf. ainda PH, \$130, 152 e 262.

${ }^{20}$ Cf. Chiron, op. cit., 2001, p. 132: Il est clair aussi que c'est à une fine observation des auteurs que Démétrios doit une seconde conception du mélange des styles. À celle qui fait se succéder les types à l'intérieur d'une cuvre, s'ajoute celle qui les mêle plus intimement, l'un donnant à l'autre son efficacité, par exemple, l'humour ou la plaisanterie mis au service de véhémence (cf. \$130-131).

${ }^{21}$ Vale ressaltar que há mais três menções feitas exclusivamente à personagem do Ciclope sem que apresentem uma relação direta com o episódio ( $\$ 115,284$ e 293); dessas três, duas (\$284 e 293) apresentam relação com ao menos um dos dois elementos e, oportunamente, serão abordadas.
} 
seguinte deve ser o de uma análise mais detida de cada uma das menções ao mesmo. ${ }^{22}$

\section{A elevação do estilo e a caracterização de um personagem monstruoso}

A primeira dessas menções ocorre no parágrafo 52. Nessa passagem, a elevação do estilo é destacada nos versos 190-192 do canto IX da Odisseia, que caracterizam o personagem de Polifemo. Nesses


essa elevação:













Como essa "ordenação dos termos" e a consequente elevação do estilo poderiam estar relacionadas com o horror é, de fato, muito arriscado conjecturar. ${ }^{24}$ No entanto, não é fora de propósito supor uma

\footnotetext{
${ }^{22}$ É digno de nota o fato de que, a par da reflexão teórica apontada como denominador comum, há uma relação estreita entre tais menções no que diz respeito ao elemento de horror contido no episódio. Seja expresso, seja apenas inferido, esse elemento está sempre presente, mesmo quando Demétrio se refere à comicidade das palavras de Polifemo a que nos referimos. E, quanto a essas últimas, vale destacar que sua própria recorrência, em três passagens, revela um interesse não menor por parte do autor, que a partir delas propõe, como salientamos, uma abordagem única entre os tratados da Antiguidade.

${ }^{23}$ Todas as traduções das passagens de Sobre o estilo reproduzidas nesse artigo são de minha autoria. Para uma tradução, na íntegra, do texto de Demétrio, cf. Freitas, op. cit., p. 102 sq.
}

${ }^{24}$ Segundo Demétrio, é preciso ordenar as palavras do seguinte modo: primeiro,


máximo evidenciadas. Pois assim, ouviremos o primeiro termo como se ele tivesse alguma evidência, e aquele que vem depois, como mais evidente ainda. Caso contrário, pareceríamos enfraquecidos, como se, em pleno vigor, tivéssemos uma recaída (\$50): "Homero também, na passagem do Ciclope, sempre aumenta a hipérbole, até mesmo a exagerando, como em: 'Pois não parecia/ com um homem 
relação, embora ela não esteja evidenciada, entre tal recurso estilístico e a caracterização física da personagem. Sem dúvida, não podemos negligenciar o fato de que, ao dizer que as primeiras coisas mostradas


"maiores" ( $\mu \varepsilon ı \zeta o ́ \nu \omega \nu)$, o autor se refira, mais precisamente, a uma questão ligada à grandeza do estilo.

Contudo, não podemos nos esquecer também de que, em outro momento da obra, Demétrio associa, ao certo, o uso de um recurso estilístico a uma característica propriamente física do objeto tratado. No parágrafo 6, ao citar Anabase IV, 4,3, em que Xenofonte descreve a chegada dos gregos ao rio Teléboa, Demétrio comenta que os colos breves $^{25}$ reproduziriam de algum modo, também, a "irrelevância" ou "pequenez" do rio:









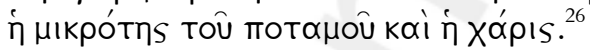

Em outras palavras, embora Demétrio não diga nada de modo suficientemente claro, pode não ser infundada a sugestão de uma analogia entre essa passagem e aquela dos versos da Odisseia, em que, logicamente, ao contrário da "pequenez" de um rio, o recurso empregado para a elevação do estilo realçaria a dimensão monstruosa do personagem.

comedor de pão, mas com um pico cheio de árvores', e, mais ainda, com um pico 'de um elevado monte que se avista acima dos demais'. De fato, sempre as coisas que vêm primeiro, mesmo sendo grandiosas, parecem ser menores quando outras, que vêm depois delas, são maiores".

${ }^{25}$ Os colos são definidos por Demétrio como elementos típicos da prosa, com função análoga aos versos na poesia. Eles delimitam o discurso, criando as pausas necessárias, tanto para quem o profere, quanto para aquilo que está sendo proferido (\$1). Segundo Lausberg (Elementos de retórica literária. Trad. R. M. Rosado Fernandes. $5^{\text {a }}$. ed. Lisboa: Calouste Gulbenkian, 2004, \453-455), o colo é uma sequência constituída de três ou mais palavras e, embora Demétrio não o explicite, os exemplos de colos, ao longo do texto, corroboram essa asserção: os menores citados são formados por três palavras, havendo, também, outros mais longos. Acerca da questão, cf. Freitas, op. cit., p. 21.

26 "Outras vezes, porém, seria a [ocasião] de um [colo] breve, ao dizermos, por exemplo, algo irrelevante, como o faz Xenofonte a respeito da chegada dos gregos ao rio Teléboa: 'Esse não era grande, mas belo'. Em virtude do ritmo curto e quebrado, surgem tanto a irrelevância do rio, quanto a graça". 


\section{O estilo elevado na cena de horror}

Ainda quanto à "elevação do estilo", vale lembrar, conforme já dissemos anteriormente, que um número expressivamente maior, entre todas as referências aos versos de Homero no tratado, encontra-se no primeiro capítulo, que diz respeito ao estilo grandioso: vinte e quatro, das quarenta e duas referências ao longo da obra, estão presentes nesse capítulo, sendo quatorze delas dedicadas, especificamente, ao estilo. ${ }^{27}$ Isso nos leva a concluir que, a par da riqueza estilística, da qual também falávamos anteriormente, o discurso elevado é, para Demétrio, a marca do estilo do poeta por excelência. ${ }^{28}$

E, no que concerne ao episódio do Ciclope, essa marca é também ressaltada em outra ocasião: no parágrafo 94 , onde Demétrio propõe como modelo de um estilo elevado o verso 394. Nesse parágrafo, o

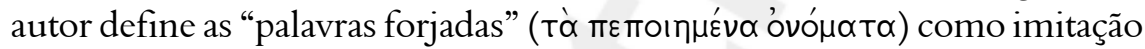

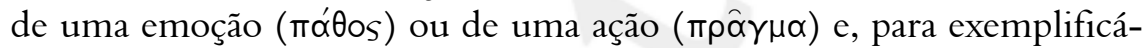
lo, o emprego do termo ó $\zeta^{29}$ é lembrado como um excelente fator de grandeza por assemelhar-se ao "som", ou "barulho" ( $\psi$ óфos), produzido pelo ato em questão e, sobretudo, por sua estranheza ( $\left.\tau \hat{\omega} \xi^{\prime} \dot{\varepsilon} v \omega\right)$.

O verbo, tal como está na Odisseia, refere-se ao barulho emitido pela ação do ferreiro ao mergulhar um ferro incandescente em água fria, e é utilizado para o momento em que o ciclope Polifemo é atingido no olho pelo tronco em brasa; a própria sonoridade da palavra evoca, nesse caso, o som de tal ato. Segundo Demétrio, o artifício do poeta estaria em usar não palavras que já existem, mas as que nascem no

\footnotetext{
${ }^{27}$ De todas as menções feitas ao poeta, quatorze referem-se a tal estilo, enquanto cinco são referentes ao estilo elegante, três ao simples, e outras três ao veemente (cf. Chiron, op. cit., 2001, p. 387-389).

${ }^{28}$ Se partirmos de uma análise acerca da questão métrica e rítmica da poesia no tratado, perceberemos que o próprio verso utilizado pelo poeta, o hexâmetro, é também identificado com o primeiro tipo de estilo descrito por Demétrio. É sabido, porém, que a abordagem apropriada da temática grandiosa passa não apenas pela escolha do metro, e, com efeito, muitos outros recursos em Homero são descritos pelo autor do $\mathrm{PH}$ como determinantes para se atingir um estilo elevado. Para uma melhor apreciação acerca dos hexâmetros e de sua relação com o estilo grandioso, cf. Freitas, op. cit., p. 34-41.

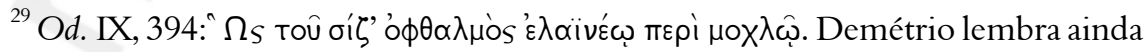

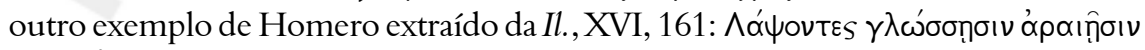

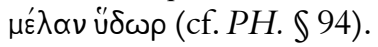


momento; mostraria, com isso, um bom engenho, ao criar uma nova palavra, assemelhando-se àqueles que primeiro as instituíram. ${ }^{30}$

\section{A cacofonia e a evocação visual do horror}

Ao certo, a relação entre estilo e horror é mais nítida em outra passagem do tratado, o parágrafo 219 , em que Demétrio ressalta o emprego da cacofonia no verso 290 do mesmo episódio. ${ }^{31}$ Segundo o autor, a cacofonia, associada à simplicidade do estilo, é vinculada a uma capacidade



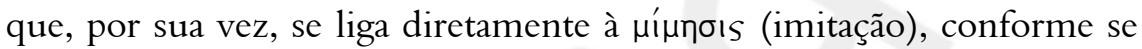
lê nas próprias palavras do autor, ainda no mesmo parágrafo: $\pi \hat{\alpha} \sigma \alpha \delta_{\varepsilon}$

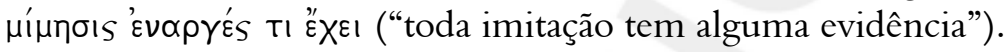

O termo $\varepsilon v \alpha \alpha \rho \gamma \varepsilon ı \alpha$, no tratado, tal como definido por Chiron, designa a faculdade de evocar, pelo estilo, a realidade concreta e dar a ilusão de vida, sendo ela ainda enriquecida pelos valores de seu parônimo

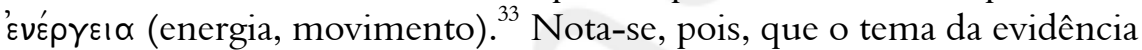
reflete a influência de uma concepção estoica da origem natural da linguagem e sua faculdade de imitar coisas e ações. ${ }^{34}$

${ }^{30} \int 95$. Como oportunamente lembrara Chiron, Demétrio parece compartilhar aqui da visão estoica a respeito da origem natural da linguagem [op. cit., 1993, p. 102 (nota 125)].

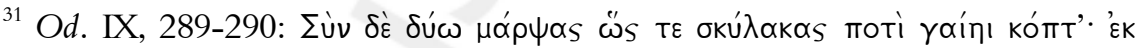

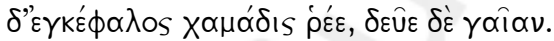

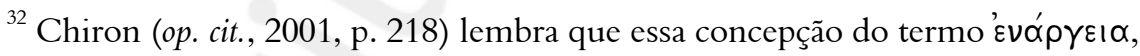
associada à capacidade de evocação visual, corresponderia àquela que se encontra



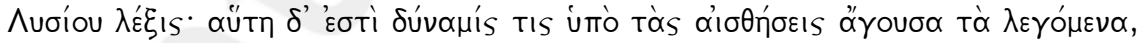


dans l'expression de Lysias: c'est un talent de faire percevoir par les sens ce qui est dit, et ce par l'indication détaillée des circonstances. - Aujac, G. Opuscules rhétoriques. Paris: Les Belles Lettres, 1981. Tome I, p. 81).

${ }^{33}$ Cf. Chiron, op. cit., 1993, p. 124, nota 277. Para uma melhor compreensão acerca do termo 'vváp $\gamma \varepsilon ı \alpha$, cf. Chiron, op. cit., 2001, p. 217-221.

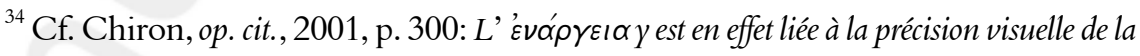
narration qui permet à l'auditeur de se représenter la scène. Ce pouvoir évocateur tient au fait que le langage, au moins le langage primitif, a pour les stoïciens, la faculté de «mimen» les choses et les actions, ayant été constitué justement par imitation du réel. Dans ces conceptions, le langage s'efface comme médiat, il a la faculté en quelque sorte de mettre la réalité sous les yeux del'auditeur ou du lecteur. 
Portanto, a cacofonia aproximaria a linguagem da ação que descreve; ação apontada pelo próprio Demétrio como uma das mais horríveis da Odisseia, conforme se pode ler no parágrafo 130. Nesse ponto, parece oportuno nos remetermos, ainda, a outro tratado da Antiguidade que se refere, de forma semelhante, à cacofonia daqueles

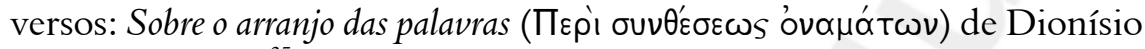
de Halicarnasso. ${ }^{35}$ Nele, não apenas uma parte do verso 290 da Odisseia é citada, como também o verso anterior, havendo uma análise um pouco mais detida da sonoridade dos mesmos: ${ }^{36}$

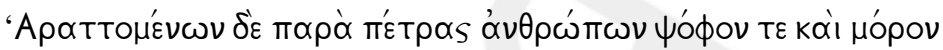

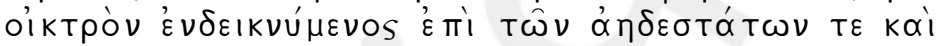

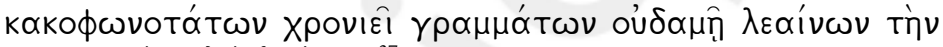

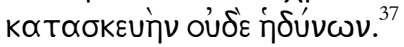

Ao analisarmos as passagens de ambos os tratados, podemos verificar que a conclusão de Dionísio não difere muito da de Demétrio, ainda que não possamos identificar uma fonte comum para eles. A cacofonia, da mesma forma que apresentada por Dionísio de Halicarnasso, reproduz, em Demétrio, o espetáculo de horror proporcionado por Polifemo, quando atira os companheiros de Odisseu contra o rochedo, antes de devorá-los. Ou seja, esta, que seria uma das mortes mais horrendas na Odisseia, a de ser devorado, ${ }^{38}$ está sendo representada também, aos nossos ouvidos, com as mais odiosas palavras.

\footnotetext{
${ }^{35}$ Mesmo que o texto de Dionísio seja considerado posterior ao tratado de Demétrio por grande parte dos comentadores (cf. supra nota 4), é bom lembrar que é possível que ambos tenham recebido influência de uma mesma tradição de leitura dos referidos versos de Homero.

${ }^{36}$ Acerca da cacofonia desses versos, vale lembrar as palavras de Packard (Soundpatterns in Homer. Transactions of the American philological association. Baltimore, vol. CIV, p. 245, 1974): This concentration of gutturals is unusual but far from unique. A single line in the "Iliad" (II. 351) has nine gutturals. No one, I think, will deny the harsh sound of these verses, but the density of guttural sounds is not the entire explanation. A major factor, as Dionysius often tells $u s$, is the distribution of consonant clashes: $\nu \delta, \rho \psi, \sigma \tau, \sigma \kappa, \sigma \pi, \pi \tau, \kappa \delta, \gamma \kappa, \sigma \chi, \sigma \rho$.

${ }^{37}$ Dionísio de Halicarnasso, DCVVI, 16, 12: "Ao demonstrar tanto o barulho quanto o lastimável destino dos homens que são chocados contra o rochedo, demora-se nas letras mais desagradáveis e mais cacofônicas possíveis, não sendo nem um pouco polido nem agradável em sua construção" (tradução minha).

${ }^{38}$ Ainda que, diferentemente do episódio de Cila, os companheiros sejam devorados depois de mortos, não deixa de ser uma morte odiosa no contexto dos valores odisseicos.
} 


\section{Horror e humor no momento mais assustador do episódio}

De fato, a cena do Ciclope atirando os companheiros de Odisseu contra o rochedo, como se fossem cãezinhos, é uma das mais assustadoras em Homero. Contudo, no parágrafo 130, Demétrio aponta, surpreendentemente, para outro momento do episódio, que seria ainda mais temível: a famosa fala de Polifemo nos versos 369 e 370: "Ninguém vou comer por último, depois dos companheiros". Segundo ele, em nenhum outro momento o poeta foi capaz de provocar tanto medo quanto nesses versos.

Sem dúvida, não negaríamos que se trata de uma cena horripilante; porém, o que nos desperta maior surpresa é o fato de que, ao caráter atemorizante da personagem, Demétrio associa justamente o elemento cômico, que, a princípio, poderíamos pensar ser oposto ao do horror. Nessa passagem, ao contrário do que se esperaria, eles estão associados a ponto de Demétrio afirmar que Homero "brincando é mais amedrontador":

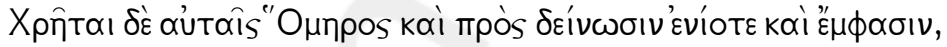

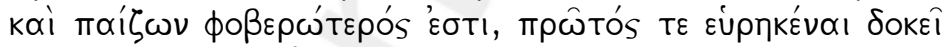

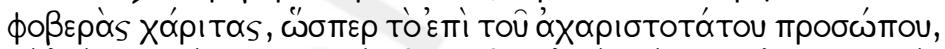

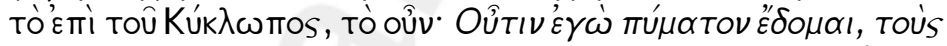



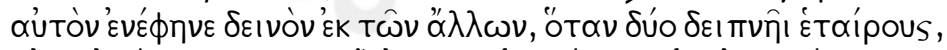

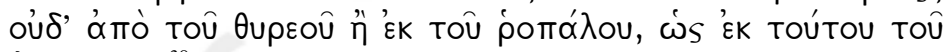

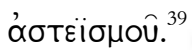

Alguns comentadores chegaram a apontar a questão do humor na citação feita por Demétrio, no entanto, não há nenhum estudo mais detalhado sobre ela. ${ }^{40}$ De fato, a sua inserção no tratado não deixa de ser um pouco problemática e carece de uma maior explanação por parte

\footnotetext{
39 "Mas, às vezes, Homero também lança mão da graça para aterrorizar e impressionar - e é mais amedrontador brincando. Aliás, ele parece ter sido o primeiro a ter encontrado a graça amedrontadora, como no episódio da mais sem graça das personagens, o Ciclope: 'Ninguém vou comer por último; os outros, primeiro' (Homero, Odisseia, IX, 369- 370; cf. infra \152, 262) - esse o dom de hospitalidade do Ciclope! Com efeito, em nenhum outro momento, o poeta o mostrou tão terrível (nem ao jantar os dois companheiros, nem nas menções à clava ou à pedra que lhe servia de porta), quanto nessa fineza".

${ }^{40}$ Chiron, a exemplo de Bompaire, propôs o termo humour noir para expressar o conteúdo da mensagem de Demétrio (cf. Bompaire, op. cit., p. 589/Chiron, op. cit., 2001, p. 137).
} 
do autor, o que pode ter sido um dos motivos para o desinteresse dos estudiosos. ${ }^{41}$ Soma-se a isso o fato de não encontrarmos, como já fora dito, nenhuma outra abordagem como essa nos tratados da Antiguidade.

Um dos principais problemas é que, no tratado de Demétrio, o termo Xápıs abarca em seu campo semântico um grande número de possibilidades, ${ }^{42}$ ainda que essas estejam desenvolvidas em torno de dois eixos principais, determinados no parágrafo 128 :

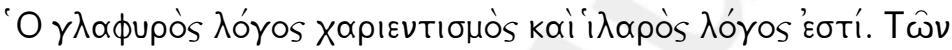

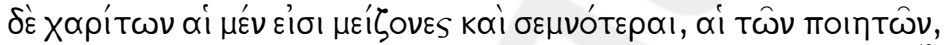

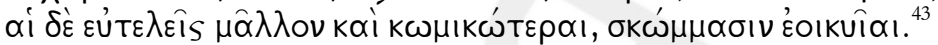

A definição de Demétrio pode parecer, à primeira vista, suficiente, não fossem os problemas relacionados, sobretudo, com o elemento cômico. ${ }^{44}$ Vários exemplos são desprovidos de qualquer elegância, o que torna problemática a inserção dos mesmos no capítulo; ${ }^{45}$ além disso, Demétrio pontua uma xópıs mais nobre e elevada própria dos poetas; no entanto, propõe exemplos do termo ligado ao cômico também entre os mesmos, como é o caso da passagem do parágrafo 130. Além do mais, ainda nesse parágrafo, Demétrio faz menção à comicidade da cena sem qualquer referência a uma possível elegância ou graciosidade.

\footnotetext{
${ }^{41}$ Cf. Schenkeveld, op. cit., 1964, p. 62: This queerness is softened if we recollect the relative independence of the sections on the Xápı tes from the whole chapter on the elegant style, but nevertheless a further explanation by Demetrius himself would have been helpful.

${ }^{42}$ Acerca dessas possibilidades no PH, cf. Chiron, op. cit., 2001, p. 284-286.

43 "O discurso elegante é cheio de graça, sendo também um discurso agradável. E, dentre os tipos de graça, uns são mais elevados e mais nobres, os dos poetas. Outros são mais comuns e mais cômicos, parecidos com escárnios".

${ }^{44}$ Com relação a isso, vale reproduzir as observações de Grube (op. cit., 1961, p. 31): At the very beginning (128) we are told that elegant language may be described as a gay playfulness of expression. The charm is then said to be of two kinds: on the one hand the graceful poetic charm of such passages as Homer's description of Nausicaa playing among her handmaidens; and, on the other hand, witticism. The difficulty is that too much is included under the second: the witticism quoted at the very beginning (e.g. the old woman's teeth are sooner counted than herfingers) have no trace of charm, or indeed of elegance or grace. Moreover, this is true of many other jests quoted; for example, the grim humour of the Cyclops.

${ }^{45}$ Lembro as palavras de Chiron (op. cit., 2001, p. 137): La gamme expressive de ce style est plus variée, le seul dénominateur commun étant la gaieté: ce peut être le fin mot d'esprit (\$149), la comparaison piquante (\$160), l'humour "noir" (\$130) ou, plus subtilement encore, le soulagement après un frayeur (\$155).
} 
Outra questão que deve ser levantada é a da associação entre o estilo elegante e o veemente, a qual, nessa passagem, se dá por meio

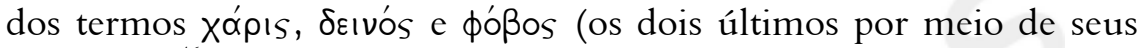
derivados). ${ }^{46}$ Schenkeveld aponta para a excepcionalidade no tratado:

The elegant style is found mixed with the plain and the grand, and so is the forcible style. A mixture of the elegant and forcible styles is not mentioned and indeed Demetrius contrasts them in $\$ 258$ from the composition point of view (...) Nevertheless $\$ \mathbb{S}$

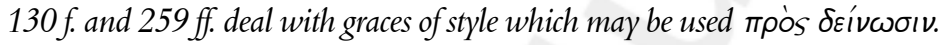
Obviously we detect here an unevenness in Demetrius' theory of types of style, which

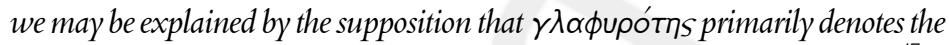
smoothness of composition, but has been expanded to the others aspects as well. ${ }^{47}$

Não se pode, no entanto, afirmar que essa situação excepcional represente uma incoerência de fato. Conforme já dissemos, está expresso no parágrafo 36, que os únicos estilos que não se misturam são o "grandioso" e o "simples". Também, quanto à afirmação de que os outros dois estilos seriam intermediários e que o elegante ( $\gamma \lambda \alpha \phi u p o ́ s)$ se ligaria mais ao simples (ioxvós), é oportuno lembrar que Demétrio simplesmente a ridiculariza; além do mais, um dos exemplos em que tal "mescla" se encontra é justamente a poesia de Homero. Já sobre a

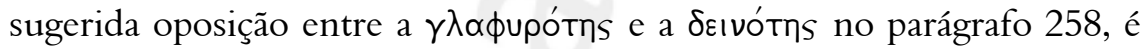

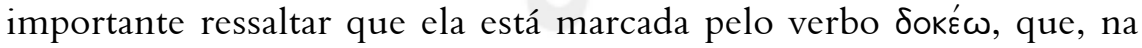
terceira pessoa do plural, expressaria que tais termos "parecem" e não exatamente "são" opostos. Chiron resume bem essa questão:

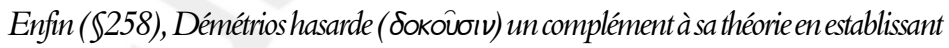
entre le style véhément et le style élégant une relation d'opposition ('Evavтı Cette opposition est assez convaincante à condition de ne pas la mener jusqu'à une incompatibilité semblabe à celle qui oppose le grand style et le style simple ( $c p$.

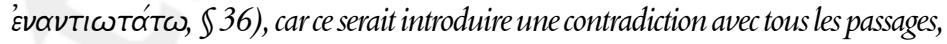
fort intéressants d'ailleurs, qui montrent, par exemple, comment l'humour, qui relèvedu style élégant, peut concourirà l'effroi, lequel ressortit à la véhémence (\$130-131,259262), bref comment le type élégant peut se mélanger au style véhément. ${ }^{48}$

\footnotetext{
${ }^{46}$ Acerca da proximidade semântica dos termos deıvós e фóßos uma excelente definição foi dada por Chiron (op. cit., 2001, p. 135): Un terme est associée à deıvós, qui montre que ce dernier mot est pourvu chez Démétrios de son sens premier: фoßepós. Le style véhément est un style quifait peur.

${ }^{47}$ Cf. Schenkeveld, op. cit., 1964, p. 54. Os outros aspectos a que se refere Schenkeveld são o "pensamento" e a "escolha de palavras".

${ }^{48}$ Cf. Chiron, op. cit., 2001, p. 120.
} 
Mas a comprovação de que não há, exatamente, uma incoerência não parece ainda suficiente para compreendermos a fundo as afirmações de Demétrio no que diz respeito à relação entre os elementos do riso e do temor. Quanto a isso, as informações que o autor nos fornece no parágrafo seguinte podem ser mais elucidativas, embora, também, ainda não resolutivas. Verificando como o mesmo recurso utilizado por Homero nos versos da fala de Polifemo é mencionado, a respeito de um trecho da obra de Xenofonte, podemos tirar uma importante conclusão:

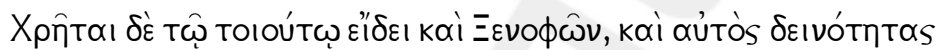

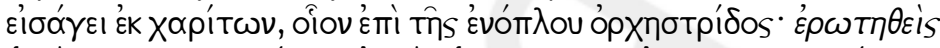

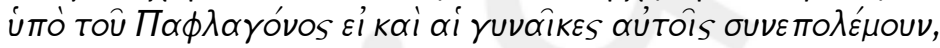

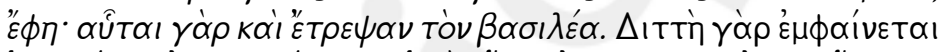

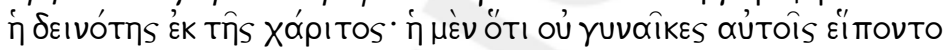

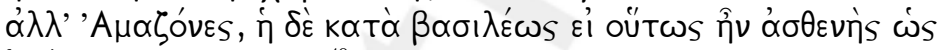

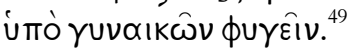

A leitura comparativa das passagens remete, pois, a algo que, a princípio, é cômico, mas que traz consigo uma realidade terrível que vai além da aparente frivolidade. Logo, pode-se concluir disso que o que possibilita o efeito cômico ao lado do atemorizante é, sem dúvida, o duplo sentido da frase. Isso não significa que ele garanta a reprodução desse efeito, mas é inegável que a sua ausência impossibilitaria tal reprodução.

A par disso, poderiam ainda nos ajudar a compreender melhor as afirmações feitas por Demétrio acerca da fala do Ciclope as informações que nos fornece a própria Odisseia acerca do episódio. Logo, no que concerne à versão odisseica do mito do Ciclope, é oportuno lembrar algumas das considerações feitas por Reece a respeito da particular abordagem de Homero - que não encontramos em nenhuma outra versão das mais de duzentas lendas espalhadas pelo mundo sobre essa figura mítica -, na qual o tema da hospitalidade permeia todo o episódio. ${ }^{50}$

49 “Também Xenofonte lança mão dessa espécie de graça e também ele promove o
terror por meio dela. Por exemplo, na passagem da dançarina em armas: 'Perguntado
pelo plafagônio se também as mulheres guerreavam ao lado deles, disse: 'Pois elas
mesmas até fizeram o rei voltar para trás'.' Por meio da graça, um duplo terror se
manifesta: um, porque não eram mulheres que os acompanhavam, mas as amazonas;
outro é contra o rei, que seria fraco a ponto de ser afugentado por mulheres”.
${ }^{50}$ De fato, poderíamos levantar a hipótese de que Demétrio teria sido influenciado
por alguma outra versão do mito do Ciclope, como, por exemplo, a do drama
satírico de Eurípides, na qual o aspecto cômico da personagem é enfatizado, e que
isso poderia, em alguma medida, ter acarretado uma leitura deturpada do texto 
In sum, Homer has transformed the inherited folktale of the blinding of a one-eyed ogre into a hospitality scene - or rather a parody of one - by introducing many typical elements of hospitality: the acquisition of gifts; the impiety of the host towards Zeus, protector of guests; the exchange of gifts, albeit deceptive ones, between guests and hosts; the revelation of the guest's name, lineage and homeland, albeit revealed at his departure rather than his arrival; the element of the curse - replacing the typical blessing-upon the departure; and a appearance of an omen upon departure. ${ }^{51}$

De fato, é legítimo pensar que Demétrio tenha uma percepção semelhante no que se refere à relação entre o episódio e as cenas típicas de hospitalidade, afinal, isso é, antes de tudo, dado pelo próprio texto da Odisseia. Conforme o próprio Reece destacou, talvez essas cenas sejam mais familiares ao público de Homero do que quaisquer outras cenas típicas.

Com efeito, o autor recorda as quatro primeiras cenas de hospitalidade - Atena-Mentes em Ítaca, Telêmaco em Pilos, Telêmaco em Esparta e Odisseu na Esquéria -, as quais mergulham completamente o público em elementos convencionais de hospitalidade, de modo que aquele é então preparado para reconhecer e apreciar os eventuais desvios

homérico. Quanto a isso, lembremos ainda que há duas passagens mencionadas em Sobre o estilo que fazem menção ao personagem do Ciclope, em um contexto diverso daquele da Odisseia, e mostram tanto o seu lado temível, quanto o cômico. No parágrafo 284, a sua imagem é tomada sob forma de alegoria para, de fato, conferir

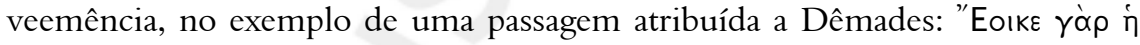

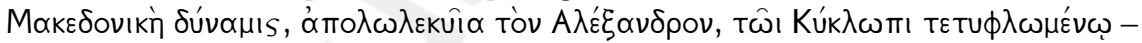
"O poder da Macedônia, após a perda de Alexandre, parecia com o Ciclope já cego". Mas, já no parágrafo 293, parece haver algo de ridículo na referência à personagem; aqui Demétrio aconselha sobre os riscos de se utilizar o "discurso figurado" na

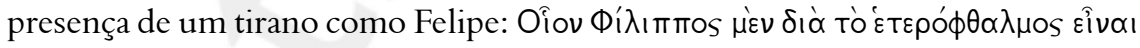

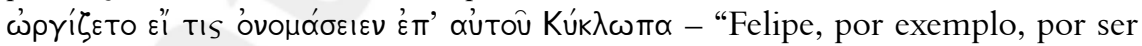
caolho, ficava em cólera se alguém pronunciasse, diante dele, 'Ciclope’”. No entanto, não podemos nos esquecer de que não há em Sobre o estilo, nenhuma menção que comprove, por exemplo, o conhecimento de Demétrio acerca da referida peça. Aliás, não há indício algum da recepção de versões do mito, diferentes daquela da Odisseia, pelo autor, e, ainda que o tivéssemos, seria provavelmente muito difícil afirmar que elas teriam exercido uma influência direta na sua leitura do texto homérico.

${ }^{51}$ Cf. Reece, op. cit., p. 130. Acerca da utilização desses elementos de uma cena típica de hospitalidade no episódio do Ciclope, destaquemos ainda a acurada análise de Pietro Pucci em op. cit.

53 Cf. Reece, op. cit., p. 125. 
dessas normas. Assim, Homero retoma a experiência prévia de sua audiência na Ciclopeia, criando o que Reece veio a chamar de "paródia de uma cena de hospitalidade". ${ }^{2}$

Ora, lembremos que, apesar de Demétrio não fazer menção direta a todos esses elementos da cena típica, há pelo menos um - e, nesse caso, o mais decisivo - ao qual o autor de Sobre o estilo irá se referir, que

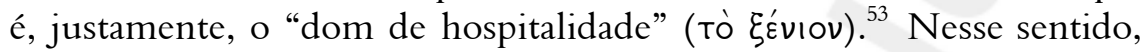
lembremos quando os mesmos versos da fala de Polifemo são retomados no parágrafo 152 :

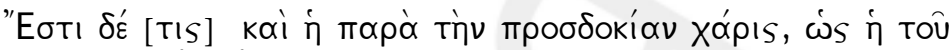

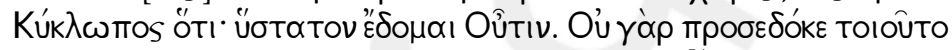

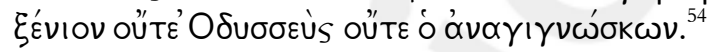

Como podemos notar, há menção a uma Xápıs que diz respeito à comicidade, ${ }^{55}$ e essa, por sua vez, está estreitamente relacionada com o efeito da "surpresa", e, mais do que isso, que essa "surpresa", desagradável

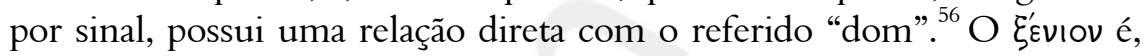
pois, na Odisseia um elemento essencial nas relações sociais e políticas no contexto dessas cenas típicas, e a expectativa por um dom como esse está, claramente, sendo violada pelo Ciclope, e de forma sarcástica. ${ }^{57}$

Entretanto, nesse ponto também é necessário fazer uma ressalva: do mesmo modo que o duplo sentido a que nos referimos antes, a "surpresa" não propicia, por si só, o efeito cômico, mas, juntamente

\footnotetext{
${ }^{53}$ Nesse ponto, parece oportuno retomar a afirmação de Reece quanto à apreensão do material tradicional pelo poeta da Odisseia: Only in Homer's version do the hero and the ogre exchange gifts (op. cit., p. 128).

54 "Há, ainda, a graça que vem junto com o inesperado, como aquela do Ciclope dizendo que: 'Por último, vou comer ninguém'. Afinal, por um dom de hospitalidade como esse, nem Odisseu nem o leitor esperavam".

${ }^{55} \mathrm{O}$ exemplo seguinte, após citação dos versos de Homero, é retirado de Aristófanes, o que sugere uma referência à veia cômica também do poeta da Odisseia.

${ }^{56}$ Cf. Reece, op. cit., p. 125: The guest gift of Polyphemus - the privilege of being eaten last (9.369-70) - is a cynical parody of the normal ritual.

${ }^{57}$ De fato, é razoável pensar que o autor do $P H$ tenha uma boa noção quanto a esse "dom" no contexto da obra de Homero; pelo menos ele mostra certo conhecimento de sua função, ao sugerir que o comportamento de Polifemo foge a regras básicas esperadas por todos. Ademais, o próprio exemplo de Aristóteles, citado no parágrafo 157, pode indicar que se reconhece minimamente a importância de tal "dom" também no contexto das relações entre os gregos na Antiguidade.
} 
com outros elementos, ela é capaz de fazê-lo. Ademais, é inegável que as palavras 'surpreendentes' do Ciclope reforçam seu caráter selvagem e impetuoso.

No entanto, ainda não nos parece possível vislumbrar, com muita clareza, o elemento cômico. A esse respeito, o parágrafo 262 parece fornecer mais pistas. Nele, os versos referentes à fala do Ciclope serão retomados, na ocasião do capítulo referente ao estilo veemente:

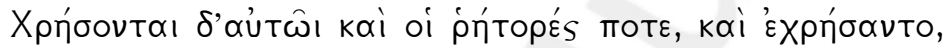

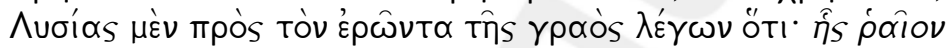

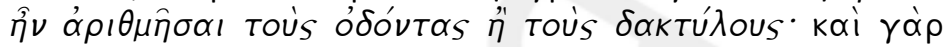

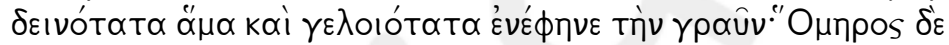

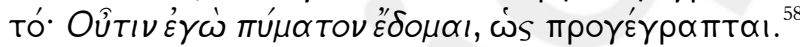

Comentamos um pouco sobre o fato de Demétrio inserir uma reflexão sobre o medo, ou sobre a veemência, no estilo elegante ou polido; mas também a presença do elemento cômico no estilo veemente não é menos relevante para nossa análise. E essa presença está, pois, relacionada com o chamado "modo cínico", cuja inserção em dado estilo encontra uma boa justificativa nas próprias palavras do autor, no parágrafo 261:

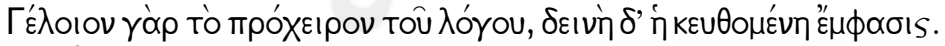

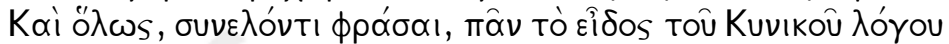

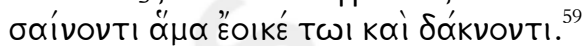

Percebe-se, por essas palavras, que aquilo que justificaria a presença do "modo cínico" em um estilo caracterizado, sobretudo, pelo

\footnotetext{
58 "Mesmo os oradores lançarão mão desse expediente, às vezes, como já o lançaram. Lísias, ao atacar o amante de uma velha, 'de quem era mais fácil contar os dentes do que os dedos', apresentou a velha com a maior veemência e de forma muitíssimo engraçada. Também Homero, na passagem anteriormente citada: 'Ninguém vou comer por último’.

59 "Do que foi dito, o que está ao alcance das mãos faz rir, mas o sentido oculto é veemente. Para resumir, em geral, em tudo o aspecto do discurso cínico é como o de um cão que abana o rabo e, ao mesmo tempo, morde”. Com relação a esse "sentido oculto" no discurso dos cínicos, lembremos o comentário de Demétrio sobre Diógenes, nas Olimpíadas, que, depois da corrida em armas, ele próprio correndo, "proclamava vencer em nobreza todos os homens": Suas palavras provocam o riso e, ao mesmo tempo, causam espanto - e, devagar, o que é dito se torna levemente mordaz $(\$ 260)$.
} 
tom ofensivo, não é tanto a expressão em si, mas antes sua real intenção. ${ }^{60}$ A expressão é, pois, marcadamente cômica, como podemos verificar no parágrafo 259, em que esse "modo" é, inclusive, mencionado ao lado da própria comédia:

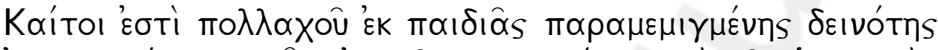

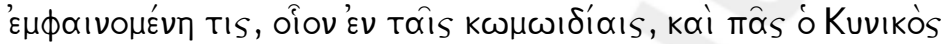
тро́тоо. ${ }^{61}$

É oportuno lembrar que os versos referentes à fala do Ciclope também foram, no parágrafo 152, propostos ao lado de um exemplo retirado de uma comédia, o que sugere uma relação mais próxima do que poderia supor um leitor menos atento. Ainda, no parágrafo 259, é

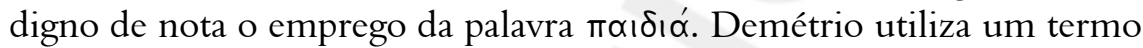

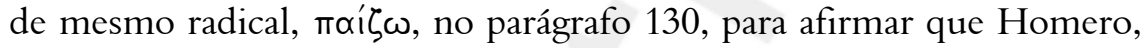
"brincando, é mais assustador". De fato, esse emprego parece portar certa ironia, uma vez que, apesar de seu radical $\pi \propto \delta_{-}$- (de "criança", em grego), ele se aplica a uma ação, nem um pouco ingênua, próxima da malícia de um ator de comédia ou das ações de um cínico, cujas reais intenções escondem-se por detrás de uma aparência frívola ou ridícula. ${ }^{62}$

Desse modo, a "brincadeira" do poeta, ao invés de representar um contraponto dentro de um episódio marcado pelo horror, o torna, ao contrário, ainda mais aterrorizante. Afirmar que Homero, "brincando, é

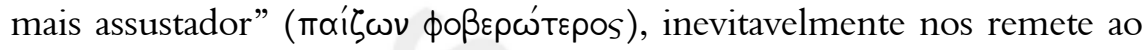
parágrafo 262, em que, ao comentar os versos da fala de Polifemo, ao lado do trecho de Lísias, afirma ele que a máxima veemência está junto

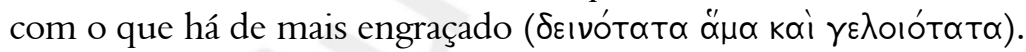

${ }^{60}$ Cf. Chiron, op. cit., 1993, p. 130: Ce << <our cynique > > est à la fois un ton et une méthode de direction morale. Il se caractérise par un mélange de sérieux, de rigueur, et de drôlerie, voire d'obscénité. On peut s'étonner de voir le thème de l'humour réapparaître dans un chapitre consacré

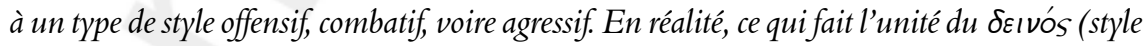
véhément) est non pas tant son expression que sa visée. Or les cyniques visent bien à corriger les hommes vigoureusement.

61 "De fato, muitas vezes, há uma veemência que se manifesta a partir de uma brincadeira que se mistura a ela, como nas comédias e em todo o modo cínico”.

${ }^{62}$ É interessante notar, nas palavras de Demétrio, que parece haver uma reflexão sobre o próprio riso e seu poder de dissimular, desde uma intenção moralizante, até uma ameaça mais cruel. Quanto ao Ciclope, é oportuno lembrar, a exemplo do que propõe Pietro Pucci, como em outros momentos do episódio, Polifemo "brinca com as palavras" (op. cit., p. 127). 
E, assim, com todas essas informações, podemos, afinal, encontrar uma melhor interpretação para as menções feitas por Demétrio ao trecho mais assustador da Odisseia. O método do Ciclope aproximarse-ia, então, daquele de um cínico, com a diferença de que este propõe uma brincadeira com o propósito moralizante, enquanto a intenção de Polifemo é claramente muito mais maligna. ${ }^{63} \mathrm{E}$, enfim, fica melhor esclarecida a questão do humor nas palavras desse personagem e do duplo sentido, a que nos referimos antes, relacionado com a intenção que se esconde por detrás de um sentido aparente. Ademais, vimos que o efeito da "surpresa", por sua vez, pautado na transgressão de uma norma básica de conduta, é um artifício importante que garante a eficácia do humor. E compreendemos, afinal, por que o elemento cômico não apenas se mostra presente nessa cena, marcadamente de horror, mas antes, se coloca a serviço do mesmo para torná-lo ainda maior.

\section{Referências}

AUJAC, G. Denys d'Halicarnasse. Opuscules rhétoriques. Paris: Les Belles Lettres, 1981. Tome I.

AUJAC, G. \& LEBEL, M. Denys d'Halicarnasse. Opuscules rhétoriques. Paris: Les Belles Lettres, 1978. Tome III.

BOMPAIRE, J. Lucien Écrivan. Imitation et création. Paris: Les Belles Lettres, 2000, p.33-43.

CHIRON, P. Un rhéteur méconnu: Démétrios (Ps.- Démétrios de Phalère). Essai sur les mutations de la théorie du style à l'époque hellénistique. Paris: Librairie Philosophique J. Vrin, 2001.

.Démétrios. «Du style». Paris: Les Belles Lettres, 1993.

CLASSEN, C. J. Rhetoric and literary criticism. Their nature and their functions in Antiquity. Mnemosyne. Leiden, vol. XLVIII, p. 513-535, 1995.

FREITAS, G. A. "Sobre o estilo" de Demétrio: um olhar crítico sobre a Literatura Grega (tradução e estudo introdutório do tratado). Dissertação de mestrado inédita. Belo Horizonte: FALE-UFMG, 2011 (177f).

GRUBE, G. M. A. The Greek and Roman critics. Indianapolis: Hackett Publishing Company, Inc., 1995.

1961.

. A Greek critic: Demetrius "On style". Toronto: University of Toronto Press:

${ }^{63}$ Nesse ponto, lanço mão das palavras de Pietro Pucci (op. cit., p. 117): The Cyclops is more ironic and more subtle than his gullibility in the 'Nobody' scene might suggest. 
INNES, D. C. Demetrius. "On style” (in Aristotle, v. XXIII). London: Harvard University Press, 2005.

. Reviewed work(s): studies in Demetrius "On style" by Dirk Marie Schenkeveld. The classical review, new series. Cambridge, vol. XVI, n. 3, p. 315-317, dec. de 1966.

KENNEDY, G. A. Classical rhetoric E its christian E secular tradition from ancient to modern times. $2^{\text {nd }}$ ed., rev. and enl. Chapel Hill: University of North Carolina Press, 1999, p. 127-136.

. A new history of classical rhetoric. Princeton, New Jersey: Princeton University Press, 1994, p. 81-101.

. Reviewed work(s) - A Greek Critic: Demetrius 'On style' by G. M. A. Grube. The American journal of philology. Baltimore, vol. LXXXIV, n. 3, p.313-317, jul., 1963. . The art of persuasion in Greece. Princeton: Routledge \& Kegan Paul, 1963.

LAUSBERG, H. Elementos de retórica literária. Trad. R. M. Rosado Fernandes. $5^{\mathrm{a}}$. ed. Lisboa: Calouste Gulbenkian, 2004.

LÓPEZ, J. G. Demetrio, "Sobre el estilo”, 'Longino', "Sobre el sublime”. Madrid: Gredos, 1996.

MORPURGO-TAGLIABUE, G. Demetrio: dello stile. Roma: Edizioni dell'Ateneo, 1980.

PACKARD, D. W. Sound-Patterns in Homer. Transactions of the American philological association. Baltimore, vol. CIV, p. 239-260, 1974.

PERNOT, L. La Rhétorique dans l'Antiquité. Paris: Librairie Génerale Française, 2000.

PUCCI, P. The I and the other in Odysseus's story of the Cyclopes. In:

(org.). The song of the sirens. Essays on Homer. Lanham: Rowman \& Littlefield Publishers, 1998, p. 113-130.

REECE, S. Polyphemus ("Od”. 9. 105-564). In: (org.). The stranger's welcome. Oral theory and the aesthetics of the homeric hospitality scene. Ann Arbor: The Michigan University Press, 1993.

ROBERTS, W. R. Demetrius “On style", the Greek text of Demetrius "De elocutione”. Edited after the Paris manuscript, with introduction, translation, facsimiles, etc. Cambridge: Cambridge University Press, 1902.

SCHENKEVELD, D. M. The intended public of Demetrius's On style: the place of the treatise in the hellenistic educacional system. Rhetorica. Leiden, vol. XVIII, n. 1, p. 29-48, 2000.

. Studies in Demetrius “On style”. Amsterdam: A. Hakkert, 1964. 